\title{
De volta à economia de merda
}

\author{
Tradução por Fábio Tozi e João Lucas Xavier
}

Resumo: $O$ texto discute as medidas de isolamento (lockdown) durante a pandemia de COVID-19 como um momento exemplar para debater 0 sentido da economia. $O$ isolamento provou que uma grande parcela dos trabalhos que as pessoas desenvolvem são inúteis e não fazem falta, sendo, logo, "trabalhos de merda" (bullshit jobs). Ao mesmo tempo, os trabalhos que envolvem diretamente cuidar de outras pessoas se mostram essenciais, embora sejam aqueles de mais baixa remuneração. Essa constatação é um risco à burocracia corporativa e estatal criada para permitir uma apropriação privada da riqueza e que sustenta a existência dos "trabalhos de merda". Por isso, é necessário retomar "a economia" rapidamente, mesmo que ela seja uma economia inútil, ou de merda (bullshit economy). Finalmente, questiona-se se a definição de economia pela noção de produtividade não seria uma ideia já ultrapassada.

Palavras-chave: pandemia; economia de merda; produtividade; economia do cuidado; trabalhos de merda.
Abstract: The article discusses the lockdown during the COVID-19 pandemic as an exemplary moment to debate the contemporary direction of the economy. The lockdown proved that most of the jobs that people do are useless and not necessary and could be considered as bullshit jobs. At the same time, caring jobs are essential, although they are among those with the lowest wages. This finding is a risk to corporate and government bureaucracies designed to produce private debt and which support bullshit jobs. Therefore, it is necessary to restart "the economy" quickly, even if it is a bullshit economy. Finally, it is asked whether the definition of the economy by the notion of productivity would not be an outdated idea.

Keywords: pandemic; bullshit economy; productivity; caring economy; bullshit jobs.
Este é um artigo publicado em acesso aberto (Open Access) sob a licença Creative Commons Attribution, que permite uso, distribuição e reprodução em qualquer meio, sem restrições desde que sem fins comerciais e que o trabalho original seja corretamente citado.

\footnotetext{
1 Tradução de Fábio Tozi (Professor Adjunto no Instituto de Geociências da Universidade Federal de Minas Gerais) e João Lucas Xavier (Graduando em Geografia na Universidade Federal de Minas Gerais) a partir do original em inglês (também disponível nesta revista) de Vers une "bullshit economy", publicado originalmente no jornal francês Libération de 27 de maio de 2020 e disponível em: www.liberation.fr/debats/2020/05/27/vers-une-bullshit-economy_1789579. O texto original não possuía título, resumo, palavras-chaves e referências, que foram acrescidos pelos tradutores. $A$ tradução para o português foi autorizada por Nika Dubrosky, companheira de David Graeber, a quem os tradutores agradecem pela gentileza e confiança.

2 Professor de Antropologia na London School of Economics and Political Science.
} 
No Reino Unido e nos Estados Unidos, fala-se sem parar sobre a necessidade de "reiniciar a economia", para "fazer nossa economia voltar a funcionar a pleno vapor", entre outas frases semelhantes. Isso soa como se a economia fosse algum tipo de imensa turbina barulhenta que foi temporariamente desligada e precisa ser colocada novamente em operação o mais rápido possível. Somos frequentemente encorajados a pensar a economia dessa maneira, ainda que nos tenham dito até recentemente que ela era uma máquina que funcionava por conta própria; certamente não tinha um botão para "pausar" ou "desligar" e, se tivesse, pressioná-lo seria instantaneamente catastrófico. Mas o fato de tal interruptor existir é certamente interessante. E alguém poderia indagar: $\bigcirc$ que exatamente queremos dizer com "a economia"? Afinal, se uma economia é simplesmente a maneira de manter as pessoas vivas, alimentadas, vestidas, alojadas e até mesmo entretidas, então para a maioria de nós a economia ainda estava funcionando perfeitamente bem durante $O$ isolamento. Se a economia não é o fornecimento de bens e serviços essenciais, então o que exatamente ela é?

Obviamente, existem muitas atividades da vida social - de cafés a pistas de boliche ou universidades - que qualquer pessoa razoável gostaria de ver funcionando novamente. Mas isso é o que a maioria das pessoas chama de "vida", não de "a economia". Não é sobre a vida, definitivamente, que os políticos estão falando. Mas já que eles estão dizendo às pessoas para arriscarem suas vidas pelo bem da economia, é crucial entender o que querem dizer com este termo.

Muito embora seja hoje em dia tratada como um fato natural, a própria ideia de que algo chamado "a economia" exista é um conceito relativamente recente. Essa expressão não significaria nada para Lutero, Shakespeare ou Voltaire. Mesmo após a ampla aceitação de sua existência, a sua referência continuou mudando. Quando o termo "economia política" se popularizou pela primeira vez no início do século XIX, por exemplo, a ideia que ele trazia era muito próxima de "ecologia" (à qual está etimologicamente ligada): ambos se referiam ao que se pensava serem sistemas autorregulados que, se mantivessem seu equilíbrio natural, também produziriam algo a mais (lucro, crescimento, dádivas da natureza...) para os humanos desfrutarem.

Agora, ao que parece, chegamos ao ponto em que "a economia" se refere não a um mecanismo para prover necessidades ou mesmo desejos humanos, mas, em grande medida, para aquele algo a mais adicionado ao topo: aquilo que cresce quando o PIB aumenta. Como acabamos de aprender com o isolamento, isso é basicamente conversa fiada. Em outras palavras, chegamos ao ponto em que "a economia" é, em grande parte, apenas uma palavra-código para a "economia de merda"; é um excesso, mas não um excesso celebrado por sua própria inutilidade, como os aristocratas puderam fazer anteriormente, mas um excesso agressivamente promovido como a esfera da necessidade, da "utilidade", da "produtividade" ou do realismo obstinado.

Ora, o que estamos sendo solicitados a reiniciar quando reiniciarmos "a economia" é precisamente esse setor de merda, no qual os gerentes supervisionam outros gerentes, o mundo dos consultores de relações públicas, operadores de telemarketing, gerentes de marca, chefes estratégicos e vice-presidentes de desenvolvimento criativo (e suas legiões de assistentes), administradores de escolas e hospitais, aqueles que recebem 
consideráveis quantias para desenhar os gráficos das ostentosas revistas corporativas internas de empresas nas quais o operariado é acelerado, reduzido ou forçado a cumprir burocracias desnecessárias e intermináveis. Todas aquelas pessoas cujo trabalho é, em última instância, nos convencer de que a existência de seus empregos não é uma aberração. No mundo corporativo, mesmo antes do isolamento, grandes porções de numerosos trabalhadores já estavam intimamente convencidas de que não contribuíam em nada para a sociedade. Agora que quase todos eles estão trabalhando em casa, são forçados a enfrentar o fato de que a parte relevante de seu trabalho pode ser realizada em talvez quinze minutos por dia, ou mesmo as tarefas que realmente precisam ser feitas presencialmente nas empresas onde trabalham (caso existam) estão funcionando melhor na ausência deles.

O véu foi levantado. Os apelos para "fazer a economia funcionar de novo" são, acima de tudo, vozes de políticos temerosos de que, se o véu permanecer levantado por muito tempo, será impossível esquecer o que foi vislumbrado por baixo.

Essa questão é de importância crucial para as classes políticas porque se trata, em última análise, de uma questão de poder. Todos esses exércitos de lacaios, preenchedores de caixinhas, tapaburacos$^{1}$ são mais bem compreendidos, penso eu, como $\circ$ equivalente contemporâneo dos servos feudais. Sua existência é a consequência lógica da financeirização, de um sistema no qual os lucros corporativos são cada vez mais baseados não na produção ou mesmo no marketing de algo que foi produzido, mas na aliança (interligada e cada vez mais indistinguível) entre as burocracias corporativas e as governamentais projetadas para produzir dívida privada. Para dar um exemplo do que isso significa na prática: recentemente, uma amiga artista começou a produzir máscaras em massa para distribui-las gratuitamente aos trabalhadores da linha de frente. Rapidamente ela recebeu um aviso de que não teria permissão para distribuir máscaras, mesmo gratuitamente, sem ter solicitado uma licença muito custosa. Isso, por sua vez, exigiria um empréstimo; portanto, a demanda real não é apenas que ela comercialize sua operação, mas também que o sistema financeiro receba sua parte de quaisquer receitas futuras. Obviamente, qualquer sistema baseado na simples extração de dinheiro terá que redistribuir pelo menos uma parte da pilhagem para conquistar a fidelidade de determinadas parcelas da população: estas são, no caso, as classes gerenciais. Por isso, os empregos de merda.

Como a crise de 2008 revelou, os mercados financeiros globais são basicamente apenas formas de especulação sobre oportunidades futuras de extração de renda. Todo o sistema é, em última análise, fundado no poderio militar estadunidense; em 2003, de fato, Immanuel Wallerstein até sugeriu que era disso que tratava $\circ$ Consenso de Washington dos anos 1990: em pânico com o declínio de sua dominação industrial e com o avanço inexorável da

\footnotetext{
1 Em Bullshit jobs (GRAEBER, 2018, sem tradução para o português), Graeber relata seu processo de pesquisa: enviou, por redes sociais virtuais, sua proposta sobre os "trabalhos de merda" e recebeu centenas de relatos de pessoas que consideravam seu próprio trabalho inútil. Então o autor organizou as respostas em uma tipologia com cinco grandes tipos de "trabalhos de merda": i) flunkies (lacaios); ii) goons (paus-mandados); iii) duct-tapers (tapa-buracos); box-tickers (preenchedores de caixinhas) e taskmasters (mestres de obras). Traduções dessa tipologia foram propostas por FERNANDES, 2020.
} 
Europa, do Leste Asiático e dos BRICS [Brasil, Rússia, Índia, China e África do Sul], o império americano fez uma última tentativa para frear seus concorrentes insistindo em "reformas de mercado" cujo efeito principal seria impor aos seus concorrentes $\circ$ mesmo sistema ridiculamente dispendioso de burocracia corporativa que existia nos Estados Unidos. É esse tipo de pessoas que homens como Donald Trump ou Boris Johnson estão insistindo para que sejam levadas de volta ao trabalho: não as pessoas que produzem as máscaras, mas as pessoas que concebem as taxas de licenciamento.

Obviamente, há muitos trabalhos paralisados com os quais estaríamos melhores se fossem retomados; mas há, talvez, ainda mais trabalhos que nos fariam bem se não existissem mais especialmente se quisermos evitar uma catástrofe climática total (podemos refletir sobre quanto carbono foi lançado ao ar e quantas espécies foram perdidas para sempre apenas para alimentar a vaidade dos burocratas corporativos que preferem organizar seus subordinados em cintilantes torres de escritórios ao invés de permitir que trabalhem em casa). Se tudo isso não parece extremamente óbvio, se a lógica de reabrir a economia faz algum sentido para nós, é porque fomos ensinados a pensar nas economias em termos desta velha categoria do século XX, a "produtividade". É verdade inconteste que muitas fábricas (mas não todas) estão fechadas. Eventualmente, os estoques existentes de geladeiras, jaquetas de couro, cartuchos de impressora, produtos de limpeza e afins terão que ser repostos. Mas uma coisa que a crise trouxe à tona é que apenas uma pequena proporção, até mesmo do trabalho mais essencial, é realmente "produtivo" nesse sentido clássico - isto é, envolve a criação de um objeto físico que não existia anteriormente. Acontece que boa parte do trabalho essencial é na verdade alguma variação do trabalho de cuidado: cuidar ou assistir a alguém, ensinar, transportar, consertar, limpar e manter coisas, atender às necessidades ou fornecer condições para o florescimento de outros seres vivos. As pessoas estão começando a perceber que, desse modo, nosso sistema de remuneração é profundamente perverso, pois quanto mais o trabalho de uma pessoa envolve cuidar ou mesmo beneficiar outras de alguma forma direta, menor é a chance de que ela seja paga por isso.

Pouco se nota $\circ$ quanto $\circ$ culto à "produtividade", que opera principalmente para justificar tais arranjos, chegou, mesmo em seus próprios termos, ao ponto da autossabotagem. Tudo deve ser produtivo: nos Estados Unidos, as estatísticas do Federal Reserve [Banco Central americano] medem até a "produtividade" do mercado imobiliário! O que demonstra, no mínimo, que o termo tem sido usado como um eufemismo para "lucro". Mas essas estatísticas também mostram que a "produtividade" dos setores de saúde e educação está em queda. Quando investigamos esse ponto, a explicação acaba sendo que esses setores de cuidados são os que mais estão submersos em oceanos cada vez maiores de papeladas que servem, em última análise, para traduzir resultados qualitativos em números que podem ser lançados em planilhas de Excel a fim de provar que esses trabalhos são, de alguma forma, "produtivos" - e, claro, tornando mais difícil ensinar, assistir ou fornecer cuidados aos que precisam. Uma vez que os fazedores de contas e os especialistas em eficiência foram os primeiros a fugir de hospitais e clínicas durante a pandemia, muitos trabalhadores da linha de frente $e$ pacientes agora têm uma experiência 
direta de como as coisas funcionam de maneira muito mais eficiente sem eles.

Os apelos para "reiniciar a economia" são, enfim, exigências de que corramos o risco de morrer para devolver os fazedores de contas às suas baias de trabalho. Isso é loucura. Se "a economia" deve ter algum significado real, então certamente ela deve se referir aos meios pelos quais os seres humanos cuidam uns dos outros, de modo a permanecerem vivos (em todos os sentidos do termo). $O$ que significaria redefini-la nesses termos? De que tipo de indicadores ela necessitaria? Ou seria preciso se livrar totalmente dos indicadores? $E$ se isso se revelar impossível, se o seu conceito se provar saturado de falsas suposições, então faríamos bem ao nos lembrarmos que, não muito tempo atrás, não existia algo como "a economia". Talvez essa seja uma ideia que já tenha chegado ao seu fim.

\section{Referências}

GRAEBER, David. The utopia of rules: on technology, stupidity, and the secret joys of bureaucracy. New York: Melville House, 2015.

GRAEBER, David. Dívida: os primeiros 5000 anos. Trad. Rogério Bettoni. São Paulo: Três Estrelas, 2016 [201 1].

GRAEBER, David. Bullshit jobs: a theory. New York: Simon \& Schuster, 2018.

GRAEBER, David. Vers une "bullshit economy". Libération, 27 mai. 2020. Trad. Alexandre Pateau. Disponível em: www.liberation.fr/debats/2020/05/27 /vers-une-bullshit-economy_1789579. Acesso em: 06 set. 2020.

WEISSMAN, Suzi. The rise of bullshit jobs: an interview with David Graeber, Jacobin, 30 jun. 2018. Disponível em: https://jacobinmag.com/2018/06/bullsh it-jobs-david-graeber-work-service.

Acesso em: 30 set. 2020.

FERNANDES, Fábio (tradução). A ascensão dos empregos de merda: uma entrevista com David Graeber, Jacobin Brasil, 04 set. 2020. Entrevista concedida a Suzi Weissman. Disponível em: https://jacobin.com.br/2020/09/aascensao-dos-empregos-de-merda/. Acesso em: 20 set. 2020.

Recebido em 31.10.2020

Aceito em 10.11.2020 
Nascido em 1961, em Nova York, Graeber costumava se apresentar como um antropólogo e um anarquista. No entanto, ressaltava que não era um "antropólogo anarquista", porque tal disciplina não existe. Graduou-se pela Universidade Estadual de Nova York, realizou trabalhos antropológicos em Madagascar e obteve seu Doutorado pela Universidade de Chicago. Foi professor versado em teoria social e teoria do valor na Universidade de Yale quando, por motivações controversas, não foi recontratado. Posteriormente, foi convidado a ser professor de Antropologia Social na Universidade Goldsmith de Londres, onde passou, em suas próprias palavras, a viver em exílio e com um trabalho integral em um cargo universitário compatível com suas habilidades e seu ativismo.

Essa colocação advém do fato de que ele não era apenas um teórico. Participou dos movimentos antiglobalização do início dos anos 2000 e teve fundamental importância no Occupy Wall Street, sendo frequentemente creditado como o autor do slogan não oficial do movimento: "Nós somos os 99\%" (We are the 99\%). Mas ele insistia que o slogan - como tudo mais no movimento - foi um esforço coletivo. Nos últimos anos dedicou atenção e se envolveu com o movimento revolucionário curdo em Rojava.

Entre suas obras mais importantes estão Dívida: os primeiros 5000 anos, The utopia of rules: on technology, stupidity, and the secret joys of bureaucracy e Bullshit jobs: a theory. Estes dois últimos convergem para a discussão do caráter social e da moralidade das formas hodiernas do trabalho e da economia. Nessa proposta, que se mostrou pertinente durante a pandemia de COVID-19, os "trabalhos de merda" sustentariam esse tipo de economia, enquanto os trabalhos de cuidado (que em última análise seriam o trabalho real) fomentariam a vida.

Graeber faleceu em 2 de setembro de 2020 em Veneza, aos 59 anos. Acabara de concluir trabalhos ainda não publicados sobre ajuda mútua, solidariedade e origens das desigualdades sociais. Uma série de palestras, workshops, performances, protestos, leituras e conversas públicas ocorreu em 11 de outubro de 2020 como parte de um "Carnaval Memorial Intergaláctico" organizado para celebrar a vida e obra de Graeber, acessível em https://davidgraeber.industries.

Fábio Tozi João Lucas Xavier 